\title{
Retinopathy of Prematurity, AE
}

National Cancer Institute

\section{Source}

National Cancer Institute. Retinopathy of Prematurity, AE. NCI Thesaurus. Code C154925.

An adverse event characterized by a retinal condition of very immature infants that may be characterized by non-vascularized retinae that may lead to neovascularization, scarring, retinal detachment, and blindness. 